\title{
Current Pharmacologic Therapies and Emerging Alternatives in the Treatment of Ulcerative Colitis
}

\author{
Tetsuya Nakamura $^{\mathrm{a}}$ Masakazu Nagahori ${ }^{\mathrm{b}}$ Takanori Kanai $^{\mathrm{b}}$ \\ Mamoru Watanabe ${ }^{b}$ \\ a Department of Advanced Therapeutics for GI Diseases and b ${ }^{b}$ Department of Gastroenterology and Hepatology, \\ Graduate School, Tokyo Medical and Dental University, Tokyo, Japan
}

\section{Key Words}

Ulcerative colitis - Aminosalicylates · Corticosteroids •

Immunosuppressants $\cdot$ Biologic therapy

\begin{abstract}
Recent progress in both basic and clinical research has led us to develop sophisticated and effective medical therapy of ulcerative colitis (UC). Although classical agents such as aminosalicylates, corticosteroids and immunomodulatory drugs have remained as the gold standard for decades, their novel formulations and/or dosage regimens have changed their placements in the medical management of UC. In addition, studies have shown that a number of novel therapeutic agents, designed to target specific mechanisms involved in the inflammatory cascade, have efficacy for the treatment of UC and they will have significant clinical impacts in the near future. A clear understanding of the proven and potential benefits of both the standard and emerging therapies will be required for the optimum individual care of patients with varied clinical presentations.
\end{abstract}

Copyright $\odot 2008$ S. Karger AG, Basel

\section{Introduction}

Ulcerative colitis (UC) is a chronic inflammatory disease of the large intestine of unknown etiology. The onset of UC typically occurs during adolescence or young adulthood, and the majority of affected patients progress to relapsing and chronic disease. It, therefore, is critically important to choose an appropriate therapy for both the induction and maintenance of remission with a strategy on a long-term perspective, taking into account differences between individual patients. Although traditional therapy for UC with nonspecific anti-inflammatory drugs has remained as the gold standard, recent advances in our understanding of the pathogenesis of UC have opened avenues for the development of novel therapeutic approaches $[1,2]$. In this article, we review the updated view of currently available therapeutic modalities for UC and then introduce several newly developed agents and their potential clinical impact.

\section{Currently Available Therapies for UC}

As described above, nonspecific anti-inflammatory agents such as aminosalicylates, corticosteroids and thiopurine analogues still remain as the key drugs for the

\section{KARGER}

Fax +4161306 1234

E-Mail karger@karger.ch

www.karger.com
(2) 2008 S. Karger AG, Basel

0012-2823/08/0775-0036\$24.50/0

Accessible online at:

www.karger.com/dig
Mamoru Watanabe

Department of Gastroenterology and Hepatology

Graduate School, Tokyo Medical and Dental University

1-5-45 Yushima, Bunkyo-ku, Tokyo 113-8519 (Japan)

Tel. +81 35803 5877, Fax +8135803 0268, E-Mail mamoru.gast@tmd.ac.jp 
treatment of UC. However, this does not necessarily mean that there have been few improvements in the medical management of UC over the decades. Rather, our knowledge of the mechanisms of their action or potential adverse effects has dramatically accumulated. In addition, numerous clinical studies have led us to understand that classifying the diseases into several subcategories, depending on the severity, extension and responsiveness to corticosteroids, enables us to appropriately use these classical drugs for individual patients. Such constant progress in both basic and clinical research on the therapeutic efficacy of these agents has provided us with a large amount of information that helps us refine the algorithm for the evidence-based medical therapy of UC in a timely fashion. In this part we will briefly review the current view of the medical therapies for UC with these classical agents.

\section{5-Aminosalicylic Acid}

The use of 5-aminosalicylic acid (5-ASA) has been established as the first-line induction therapy for mild to moderate UC $[3,4]$. Although there still remains controversy about the optimum induction dose, it is well accepted that oral 5-ASA is effective in most patients and dose escalation up to $4.8 \mathrm{~g}$ /day would result in an increase in response rates [5]. Adding rectal therapy with 5-ASA for active UC might be more beneficial compared with oral 5-ASA alone, although rectal 5-ASA alone may be sufficient for some patients with active proctitis and left-sided UC [6, 7]. Importantly, oral 5-ASA is also established as first-line therapy for the maintenance of remission [3, 4]. Obvious dose-response differences have not been established [8]; however, a minimum oral daily dose of $1,500 \mathrm{mg}$ is recommended to maintain the remission.

How to achieve an improved drug delivery to an affected site is also a current topic in the use of 5-ASA. Until now, a number of formulations have been developed aiming at delivering 5-ASA in therapeutic concentrations to the distal bowel. Among these, MMX mesalazine is a newly developed multimatrix formulation of 5-ASA that includes a $\mathrm{pH}$-sensitive coat around a matrix of hydrophilic polymer containing a portion of 5-ASA, together with lipophilic excipients that encapsulate additional 5ASA, enabling 5-ASA to distribute throughout the entire colon at relatively high concentrations near the colonic epithelium [9]. A recent paper has shown that both 2.4 and $4.8 \mathrm{~g} /$ day of MMX mesalazine are effective for inducing remission of active, mild to moderate UC [10]. The important aspect is that this delivery system allows less frequent dosing (once or twice daily) compared with most current 5-ASA formulations, reflecting its slow release of the drug in its formulation. Given that patients who are nonadherent with their prescribed 5-ASA therapy are at greater risk of disease flare than those who are adherent [11], the use of MMX mesalazine would also have an impact on maintaining remission during the course of UC.

\section{Corticosteroids}

Although the use of conventional corticosteroids should be generally reserved for patients with moderate to severe diseases, mild to moderate UC patients who do not respond to 5-ASA therapy could be treated with oral corticosteroids at a dose of $30-40 \mathrm{mg} /$ day. Topical therapy with corticosteroids is also an option for patients with mild to moderate activities of disease, although this was found to be less effective than the topical therapy with 5ASA [12]. Another form of topical corticosteroids, budesonide, has been developed, minimizing systemic side effects. Although a previous study showed that topical budesonide is as efficacious as 5-ASA enema [13], the effect of its long-term use should be evaluated. As for the overall efficacy of corticosteroids, 1 population-based study showed that approximately one third of UC patients would require corticosteroids during the course of their disease, and the short-term 30-day outcomes were complete remission in 54\%, partial remission in 30\% and no response in $16 \%$ [14]. Patients who fail to respond to oral corticosteroids should be admitted to hospital for intravenous administration of corticosteroids. Placebocontrolled studies have not been performed; however, several papers described the effect of intravenous corticosteroids in this group of patients, showing a general response rate of approximately 50\% [15-18]. Contrary to their effect on the induction of remission, corticosteroids have not been shown to be beneficial for the maintenance of remission of UC $[19,20]$, and, together with the presence of a high frequency of side effects, currently available data do not support the use of corticosteroids for maintenance therapy.

\section{Azathioprine/6-Mercaptopurine}

Azathioprine (AZA) and 6-mercaptopurine (6-MP) are immunomodulators that are known to act through their metabolites, 6-thioguanine nucleotides. Until recently, the efficacy of AZA or 6-MP in patients with UC had not been fully established especially as an induction therapy. This notion was largely based on the results of double-blind, randomized, placebo-controlled trials in 
the early 1970s that showed conflicting results on the efficacy of AZA for the treatment of patients with active UC $[21,22]$. However, regarding the maintenance of remission, several recent studies have indicated their benefit in decreasing the frequency of relapses and in some steroidsparing effects $[23,24]$. Most recently, a report of a multicenter study including a large number of patients showed that long-term immunosuppression with AZA in UC was clinically effective, with a statistically significant reduction of both flare incidence and steroid requirement within the first 4 years of treatment [25]. This report also showed that treatment beyond 4 years would lead to a further reduction in the steroid requirement and further improvement of disease activity. Although this study was conducted in a retrospective manner and, therefore, future prospective studies evaluating the effects of not only AZA but also 6-MP will be needed, the result of this study is considered to provide a rationale for using AZA/6-MP as a supportive agent, particularly for patients with steroid-dependent UC.

\section{Cyclosporine/Tacrolimus}

Cyclosporine is known to act as an immunosuppressant by binding and inhibiting calmodulin-dependent calcineurin in T cells. After the initial placebo-controlled trial was reported [26], cyclosporine has emerged as a potent rescue therapy for patients presenting with steroidresistant severely active UC. Subsequent retrospective studies have also shown response rates of around $80 \%$ [27, 28]. In practice, $2-4 \mathrm{mg} / \mathrm{kg} /$ day of cyclosporine is given intravenously as a 24 -hour continuous infusion. The lack of sustained response is one of the drawbacks of cyclosporine, and, therefore, administration of AZA or 6-MP is recommended to maintain the remission for patients who show the initial response to cyclosporine [29].

Tacrolimus (FK506) is a fungus-derived immunosuppressant that is also a calcineurin inhibitor, and several uncontrolled studies have shown the efficacy of intravenous and oral tacrolimus similar to that of cyclosporine $[30,31]$. A recent report of a placebo-controlled study also showed that safety and dose-dependent efficacy of oral tacrolimus for remission-induction therapy of refractory UC [32], although the long-term efficacy was not discussed in this study. Further prospective studies will be needed to address this question, and the direct comparison of its efficacy with that of cyclosporine in treating patients with steroid-resistant UC will also be beneficial.

\section{Novel Therapies for UC}

A number of novel therapeutic approaches have been emerging in recent years as a result of cumulative advance in our understanding of the pathogenesis of UC. These new therapies, targeted at specific disease mechanisms, have the potential to provide more effective and safer treatments for UC in the near future. The underlying concept for the use of each agent and the potential clinical benefit will be briefly reviewed in this part.

\section{Infliximab}

Infliximab, a chimeric monoclonal antibody directed against TNF- $\alpha$, has revolutionized the treatment of patients with Crohn's disease and begun to have an impact on therapy for UC. The results of 2 Active Ulcerative Colitis Trial studies on the efficacy of infliximab in the treatment of UC were recently reported. The remission rates were shown to be significantly higher for the groups treated with infliximab than for the placebo group, and, in addition, infliximab was found to be effective for the maintenance of remission with corticosteroid-sparing effects in patients who had insufficiently responded to conventional therapies including 5-ASA, oral corticosteroids or immunosuppressants [33]. Although the subjects in the Active Ulcerative Colitis Trial studies did not include hospitalized patients with UC failing to respond to intravenous corticosteroids, a recent placebo-controlled study showed that infliximab was also an effective rescue therapy even in the UC patients refractory to intravenous corticosteroids [34]. These studies appear to have established the efficacy of infliximab in the treatment of severe UC; however, in order to give infliximab a definite placement in the treatment of UC, further investigation would be required to elucidate the long-term efficacy, adverse events with its prolonged therapy, etc.

\section{Cytapheresis}

Adsorptive leukocyte apheresis is a unique strategy to decrease specific populations of leukocytes by extracorporeal circulation. One method uses a column that adsorbs granulocytes and monocytes/macrophages to cellulose acetate beads without adsorbing lymphocytes (referred to as granulocytapheresis). Another technique is the use of a leukocyte removal filter column, which traps and removes most granulocytes, macrophages and lymphocytes as well as platelets (referred to as leukocytapheresis). A number of studies have shown that both of these therapies are beneficial for moderate to severe UC patients [35-39], and they have been approved in clinical 
practice in Japan. A large-scale multicenter double-blind trial using sham apheresis is currently underway in the USA, and its result is expected to establish these conceptually different approaches as nonpharmacological options in the treatment of UC.

\section{Visilizumab}

Visilizumab is a monoclonal anti-CD3 antibody that induces apoptosis in CD3 T cells. Once administered, the number of $\mathrm{T}$ cells in circulation dramatically decreases within hours. Clinical trials with visilizumab in patients with severe UC refractory to intravenous corticosteroids have demonstrated clinical benefit [40, 41]. Although the cytokine release syndromes are known to occur in most of the patients as an adverse effect of visilizumab, these preliminary results are suggestive of its clinical use as an alternative to cyclosporine in steroid-refractory UC patients.

\section{Basiliximab}

Basiliximab is a chimeric anti-CD25 monoclonal antibody that blocks the IL-2 receptor $\alpha$ chain on the surface of activated T cells. In uncontrolled studies, basiliximab was shown to have efficacy in the treatment of patients with moderate to severe UC [42, 43], presumably by sensitizing $\mathrm{T}$ cells to corticosteroids, although further investigation will be required.

\section{Tetomilast (OPC6535)}

Tetomilast is a thiazole derivative phosphodiesterase inhibitor (PDE4) capable of inhibiting the functions of activated neutrophils. It was shown to have therapeutic effects in several animal models of inflammatory bowel disease [44, 45], thereby suggesting an inhibitory effect on inflammatory processes in human UC. A recent report of a multicenter randomized controlled trial, however, showed that tetomilast did not achieve significant clinical benefit in the treatment of the patients with mild to moderate UC, although the potential benefit of tetomilast in a subgroup of patients who presented with high activity scores was implied [46]. Further clinical trials would be needed to clarify this issue.

\section{RDP58}

RDP58 is an immunomodulatory decapeptide capable of inhibiting the synthesis of proinflammatory cytokines. It disrupts the formation of the TRAF6-MyD88-IRAK complex responsible for activating several intracellular signaling pathways involved in inflammation. As a result, RDP58 inhibits the production of several cytokines including TNF $\alpha$, IFN- $\gamma$, IL-2, IL- 6 and IL-12 in both immune and epithelial cell types [47]. A recent randomized trail showed that RDP58 at a relatively higher dose was effective in mild to moderate UC [48]. The novel mode of the pharmacological action of this agent is attractive and further investigation would provide an impact on its clinical usage.

\section{MLN02}

The $\alpha 4 \beta 7$ integrin is present on the cell surface of a small population of circulating $T$ cells and involved in the migration of these cells to the gut, since its major ligand is selectively expressed on the endothelium of the vasculature in a tissue-specific manner [49]. These findings raised a reasonable question of whether blockade of $\alpha 4 \beta 7$ integrin-mediated cellular adhesion might have an effect on ameliorating inflammation in the intestine. Indeed, a recent multicenter, randomized, placebo-controlled study clearly showed that a monoclonal antibody to $\alpha 4 \beta 7$ integrin (MLN02) has efficacy for the induction of remission in patients with active UC who are receiving concomitant 5-ASA or no other treatment [50]. This result suggested that MLN02 would be an attractive alternative for patients who failed to respond to 5-ASA or corticosteroid, although data on the efficacy of MLN02 in the treatment of patients in whom therapy with corticosteroids is ineffective are not available at present.

\section{Conclusion}

Although continuous efforts to develop safe and effective therapies have greatly improved the clinical course of UC over the decades, a number of patients, particularly those who are resistant or refractory to conventional therapies, are still in need of better medical management of the disease. With the advent of numerous innovative agents that target specific mechanisms of the pathophysiologic process of UC, we are now moving into the new era in which a wide variety of agents could be an option for the treatment of UC. We have still much work to do; resolving the areas of controversy in the treatment with conventional therapies, assessing the benefits and risks of newly emerging therapies especially in comparison with the currently available therapies, and so on. However, future progress in both basic and clinical research will provide a large amount of information on the use of any agents for patients with any disease status, which allows individual patients to have maximum benefit on the basis of clinical evidence. 


\section{Acknowledgements}

This study was supported in part by grants-in-aid from the Japanese Ministry of Health, Labor and Welfare; for Scientific Research and Scientific Research on Priority Areas from the Japanese Ministry of Education, Culture, Sports, Science and Technology, as well as from the Japan Medical Association.

\section{Disclosure Statement}

The authors declare that no financial or other conflict of interest exists in relation to the content of the article.

\section{References}

1 Xavier RJ, Podolsky DK: Unravelling the pathogenesis of inflammatory bowel disease. Nature 2007;448:427-434.

$\checkmark 2$ Hibi T, Ogata H: Novel pathophysiological concepts of inflammatory bowel disease. J Gastroenterol 2006;41:10-16.

-3 Kornbluth A, Sachar DB: Ulcerative colitis practice guidelines in adults (update): American College of Gastroenterology, Practice Parameters Committee. Am J Gastroenterol 2004;99:1371-1385.

4 Carter MJ, Lobo AJ, Travis SP: Guidelines for the management of inflammatory bowel disease in adults. Gut 2004;53(suppl 5):V1V16.

5 Hanauer SB, Sandborn WJ, Kornbluth A, Katz S, Safdi M, Woogen S, Regalli G, Yeh C, Smith-Hall N, Ajayi F: Delayed-release oral mesalamine at $4.8 \mathrm{~g} /$ day ( $800 \mathrm{mg}$ tablet) for the treatment of moderately active ulcerative colitis: the ASCEND II trial. Am J Gastroenterol 2005;100:2478-2485.

-6 Marteau P, Probert CS, Lindgren S, Gassul M, Tan TG, Dignass A, Befrits R, Midhagen G, Rademaker J, Foldager M: Combined oral and enema treatment with Pentasa (mesalazine) is superior to oral therapy alone in patients with extensive mild/moderate active ulcerative colitis: a randomised, double blind, placebo controlled study. Gut 2005;54: 960-965.

7 Safdi M, DeMicco M, Sninsky C, Banks P, Wruble L, Deren J, Koval G, Nichols T, Targan S, Fleishman C, Wiita B: A double-blind comparison of oral versus rectal mesalamine versus combination therapy in the treatment of distal ulcerative colitis. Am J Gastroenterol 1997;92:1867-1871.

8 Sutherland LR, May GR, Shaffer EA: Sulfasalazine revisited: a meta-analysis of 5aminosalicylic acid in the treatment of ulcerative colitis. Ann Intern Med 1993;118: 540-549.

-9 Prantera C, Viscido A, Biancone L, Francavilla A, Giglio L, Campieri M: A new oral delivery system for 5-ASA: preliminary clinical findings for MMx. Inflamm Bowel Dis 2005; 11:421-427.
0 Sandborn WJ, Kamm MA, Lichtenstein GR, Lyne A, Butler T, Joseph RE: MMX Multi Matrix System mesalazine for the induction of remission in patients with mild-to-moderate ulcerative colitis: a combined analysis of two randomized, double-blind, placebocontrolled trials. Aliment Pharmacol Ther 2007;26:205-215.

-11 Kane S, Huo D, Aikens J, Hanauer S: Medication nonadherence and the outcomes of patients with quiescent ulcerative colitis. Am J Med 2003;114:39-43.

12 Marshall JK, Irvine EJ: Rectal corticosteroids versus alternative treatments in ulcerative colitis: a meta-analysis. Gut 1997;40: 775-781.

13 Lemann M, Galian A, Rutgeerts P, Van Heuverzwijn R, Cortot A, Viteau JM, Elewaut A, Belaiche J, Froguel E, Modigliani R: Comparison of budesonide and 5-aminosalicylic acid enemas in active distal ulcerative colitis. Aliment Pharmacol Ther 1995;9:557-562.

14 Faubion WA Jr, Loftus EV Jr, Harmsen WS, Zinsmeister AR, Sandborn WJ: The natural history of corticosteroid therapy for inflammatory bowel disease: a population-based study. Gastroenterology 2001;121:255-260.

15 Truelove SC, Jewell DP: Intensive intravenous regimen for severe attacks of ulcerative colitis. Lancet 1974;1:1067-1070.

16 Truelove SC, Willoughby CP, Lee EG, Kettlewell MG: Further experience in the treatment of severe attacks of ulcerative colitis. Lancet 1978;2:1086-1088.

17 Meyers S, Sachar DB, Goldberg JD, Janowitz HD: Corticotropin versus hydrocortisone in the intravenous treatment of ulcerative colitis: a prospective, randomized, double-blind clinical trial. Gastroenterology 1983;85:351357.

18 Jarnerot G, Rolny P, Sandberg-Gertzen H: Intensive intravenous treatment of ulcerative colitis. Gastroenterology 1985;89: 1005-1013.

19 Lennard-Jones JE, Misiewicz JJ, Connell $\mathrm{AM}$, Baron JH, Jones FA: Prednisone as maintenance treatment for ulcerative colitis in remission. Lancet 1965;1:188-189.

20 Powell-Tuck J, Bown RL, Chambers TJ, Lennard-Jones JE: A controlled trial of alternate day prednisolone as a maintenance treatment for ulcerative colitis in remission. Digestion 1981;22:263-270.
21 Jewell DP, Truelove SC: Azathioprine in ulcerative colitis: final report on controlled therapeutic trial. Br Med J 1974;4:627-630.

22 Caprilli R, Carratu R, Babbini M: Doubleblind comparison of the effectiveness of azathioprine and sulfasalazine in idiopathic proctocolitis: preliminary report. Am J Dig Dis 1975;20:115-120.

23 Hawthorne AB, Logan RF, Hawkey CJ, Foster PN, Axon AT, Swarbrick ET, Scott BB, Lennard-Jones JE: Randomised controlled trial of azathioprine withdrawal in ulcerative colitis. BMJ 1992;305:20-22.

24 Ardizzone S, Molteni P, Imbesi V, Bollani S, Bianchi Porro G: Azathioprine in steroid-resistant and steroid-dependent ulcerative colitis. J Clin Gastroenterol 1997;25:330333.

25 Holtmann MH, Krummenauer F, Claas C, Kremeyer K, Lorenz D, Rainer O, Vogel I, Bocker U, Bohm S, Buning C, Duchmann R, Gerken G, Herfarth H, Lugering N, Kruis W, Reinshagen M, Schmidt J, Stallmach A, Stein J, Sturm A, Galle PR, Hommes DW, D'Haens G, Rutgeerts P, Neurath MF: Long-term effectiveness of azathioprine in IBD beyond 4 years: a European multicenter study in 1176 patients. Dig Dis Sci 2006;51:1516-1524.

-26 Lichtiger S, Present DH, Kornbluth A, Gelernt I, Bauer J, Galler G, Michelassi F, Hanauer S: Cyclosporine in severe ulcerative colitis refractory to steroid therapy. N Engl J Med 1994;330:1841-1845.

27 Cohen RD, Stein R, Hanauer SB: Intravenous cyclosporin in ulcerative colitis: a five-year experience. Am J Gastroenterol 1999;94: 1587-1592.

-28 Santos J, Baudet S, Casellas F, Guarner L, Vilaseca J, Malagelada JR: Efficacy of intravenous cyclosporine for steroid refractory attacks of ulcerative colitis. J Clin Gastroenterol 1995;20:285-289.

29 Fernandez-Banares F, Bertran X, Esteve-Comas M, Cabre E, Menacho M, Humbert P, Planas R, Gassull MA: Azathioprine is useful in maintaining long-term remission induced by intravenous cyclosporine in steroid-refractory severe ulcerative colitis. Am J Gastroenterol 1996;91:2498-2499. 
30 Fellermann K, Tanko Z, Herrlinger KR, Witthoeft T, Homann N, Bruening A, Ludwig D, Stange EF: Response of refractory colitis to intravenous or oral tacrolimus (FK506). Inflamm Bowel Dis 2002;8:317324.

-31 Hogenauer C, Wenzl HH, Hinterleitner TA, Petritsch W: Effect of oral tacrolimus (FK 506) on steroid-refractory moderate/severe ulcerative colitis. Aliment Pharmacol Ther 2003; 18:415-423.

- 32 Ogata H, Matsui T, Nakamura M, Iida M, Takazoe M, Suzuki Y, Hibi T: A randomised dosefinding study of oral tacrolimus (FK506) therapy in refractory ulcerative colitis. Gut 2006;55:1255-1262.

33 Rutgeerts P, Sandborn WJ, Feagan BG, Reinisch W, Olson A, Johanns J, Travers S, Rachmilewitz D, Hanauer SB, Lichtenstein GR, de Villiers WJ, Present D, Sands BE, Colombel JF: Infliximab for induction and maintenance therapy for ulcerative colitis. N Engl J Med 2005;353:2462-2476.

- 34 Jarnerot G, Hertervig E, Friis-Liby I, Blomquist L, Karlen P, Granno C, Vilien M, Strom M, Danielsson A, Verbaan H, Hellstrom PM, Magnuson A, Curman B: Infliximab as rescue therapy in severe to moderately severe ulcerative colitis: a randomized, placebo-controlled study. Gastroenterology 2005;128:1805-1811.

- 35 Hanai H, Watanabe F, Takeuchi K, Iida T, Yamada M, Iwaoka Y, Saniabadi A, Matsushita I, Sato Y, Tozawa K, Arai H, Furuta T, Sugimoto K, Bjarnason I: Leukocyte adsorptive apheresis for the treatment of active ulcerative colitis: a prospective, uncontrolled, pilot study. Clin Gastroenterol Hepatol 2003; 1:28-35.

36 Hanai H, Watanabe F, Yamada M, Sato Y, Takeuchi K, Iida T, Tozawa K, Tanaka T, Maruyama Y, Matsushita I, Iwaoka Y, Kikuch K, Saniabadi AR: Adsorptive granulocyte and monocyte apheresis versus prednisolone in patients with corticosteroiddependent moderately severe ulcerative colitis. Digestion 2004;70:36-44.
7 Naganuma M, Funakoshi S, Sakuraba A, Takagi H, Inoue N, Ogata H, Iwao Y, Ishi H, Hibi T: Granulocytapheresis is useful as an alternative therapy in patients with steroidrefractory or -dependent ulcerative colitis. Inflamm Bowel Dis 2004;10:251-257.

38 Sawada K, Kusugami K, Suzuki Y, Bamba T, Munakata A, Hibi T, Shimoyama T: Leukocytapheresis in ulcerative colitis: results of a multicenter double-blind prospective casecontrol study with sham apheresis as placebo treatment. Am J Gastroenterol 2005; 100 : 1362-1369.

39 Emmrich J, Petermann S, Nowak D, Beutner I, Brock P, Klingel R, Mausfeld-Lafdhiya P, Liebe S, Ramlow W: Leukocytapheresis (LCAP) in the management of chronic active ulcerative colitis - results of a randomized pilot trial. Dig Dis Sci 2007;52:2044-2053.

40 Plevy SE, Salzberg BA, Regueiro M: A humanized anti-CD3 monoclonal antibody, visilizumab, for treatment of severe steroidrefractory ulcerative colitis: preliminary results of a phase I study. Gastroenterology 2003;124:A7.

41 Targan SR, Salzberg BA, Mayer L: A phase I-II study: multiple dose levels of visilizumab are well tolerated and produce rapid and sustained improvement in ulcerative colitis patients refractory to treatment with intravenous steroids (IVSR-UC). Gastroenterology 2005; 128(suppl 2):A-75.

42 Creed TJ, Norman MR, Probert CS, Harvey RF, Shaw IS, Smithson J, Anderson J, Moorghen M, Gupta J, Shepherd NA, Dayan CM, Hearing SD: Basiliximab (anti-CD25) in combination with steroids may be an effective new treatment for steroid-resistant ulcerative colitis. Aliment Pharmacol Ther 2003; 18:65-75.
43 Creed TJ, Probert CS, Norman MN, Moorghen M, Shepherd NA, Hearing SD, Dayan CM: Basiliximab for the treatment of steroid-resistant ulcerative colitis: further experience in moderate and severe disease. Aliment Pharmacol Ther 2006;23:1435-1442.

44 Nagamoto H, Maeda T, Haruta JP, Miyakoda G, Sekiguchi K, Osaka T, Nakashima T, Kikuchi M: OPC-6535, a novel oral thiazole compound, suppresses colonic damage in a rat model of TNBS-induced colitis. Gastroenterology 2006;26(suppl 2):M1044.

45 Nagamoto H, Maeda T, Haruta JP, Miyakoda G, Mori T, Tominaga M: OPC-6535 suppresses symptoms and colonic damage in a rat model of DSS-induced chronic colitis. Gastroenterology 2006;26(suppl 2):M1045.

46 Schreiber S, Keshavarzian A, Isaacs KL, Schollenberger J, Guzman JP, Orlandi C, Hanauer SB: A randomized, placebo-controlled, phase II study of tetomilast in active ulcerative colitis. Gastroenterology 2007; 132:76-86.

47 Iyer S, Lahana R, Buelow R: Rational design and development of RDP58. Curr Pharm Des 2002;8:2217-2229.

48 Travis S, Yap LM, Hawkey C, Warren B, Lazarov M, Fong T, Tesi RJ: RDP58 is a novel and potentially effective oral therapy for ulcerative colitis. Inflamm Bowel Dis 2005;11: 713-719.

49 Briskin M, Winsor-Hines D, Shyjan A, Cochran N, Bloom S, Wilson J, McEvoy LM, Butcher EC, Kassam N, Mackay CR, Newman W, Ringler DJ: Human mucosal addressin cell adhesion molecule-1 is preferentially expressed in intestinal tract and associated lymphoid tissue. Am J Pathol 1997;151:97-110.

50 Feagan BG, Greenberg GR, Wild G, Fedorak RN, Pare P, McDonald JW, Dube R, Cohen A, Steinhart AH, Landau S, Aguzzi RA, Fox IH, Vandervoort MK: Treatment of ulcerative colitis with a humanized antibody to the alpha4beta7 integrin. N Engl J Med 2005; 352:2499-2507. 